\title{
ANÁLISE DO SETOR INDUSTRIAL DO RIO GRANDE DO NORTE: UMA ABORDAGEM ESPACIAL PARA OS ANOS 2002 E 2012
}

\author{
Elaine Carvalho de Lima ${ }^{1}$ \\ Calisto Rocha de Oliveira Neto ${ }^{2}$ \\ Janaina da Silva Alves ${ }^{3}$
}

\begin{abstract}
Resumo: O presente trabalho busca verificar a ocorrência de dependência espacial no estoque do emprego formal no setor industrial do Rio Grande do Norte, para os anos 2002 e 2012. Em termos metodológicos, o estudo se desenvolveu por meio de uma pesquisa bibliográfica e utilização da análise do Quociente Locacional e do instrumental da Análise Exploratória de Dados Espaciais (AEDE), na tentativa de identificar as aglomerações industriais existentes no território potiguar. Embora a indústria de transformação do $\mathrm{RN}$ seja beneficiada por programas de desenvolvimento industrial, como o Programa de Apoio ao Desenvolvimento Industrial do Rio Grande do Norte (PROADI), os resultados apontaram que durante o período de análise, o possível transbordamento esperado entre as áreas vizinhas se mostrou fraco e concentrado em poucas áreas desse estado.
\end{abstract}

Palavras-chave: Economia Regional; Emprego Industrial; Dependência Espacial

\section{ANALYSIS OF THE INDUSTRIAL SECTOR OF RIO GRANDE DO NORTE: A SPACE APPROACH FOR THE YEARS 2002 AND 2012}

\begin{abstract}
The present study seeks to verify the occurrence of spatial dependence in the stock of formal employment in the industrial sector of Rio Grande do Norte for the years 2002 and 2012. In methodological terms, the study was developed through a bibliographical research and use of the analysis of the Locational Quotient and of the instruments of the Exploratory Spatial Data Analysis (ESDA), in an attempt to identify the existing industrial agglomerations in the Potiguar territory. Although the RN industry receives stimulus for industrial development programs, such as the Rio Grande do Norte Industrial Development Support Program (PROADI), the results showed that during the period of analysis, the possible overflow between neighboring areas is weak and has been in areas of state.
\end{abstract}

Keywords: Regional Economy; Industrial Employment; Space Dependence

\section{ANÁLISIS DEL SECTOR INDUSTRIAL DEL RÍO GRANDE DEL NORTE: UN ENFOQUE ESPACIAL PARA LOS AÑOS 2002 Y 2012}

Resumen: El presente trabajo busca verificar la ocurrencia de dependencia espacial en el stock del empleo formal en el sector industrial de Rio Grande do Norte, para los años 2002 y 2012. En términos metodológicos, el estudio se desarrolló por medio de una investigación

\footnotetext{
${ }^{1}$ Doutoranda em Economia pela Universidade Federal de Uberlândia (UFU). Mestre e graduada em economia pela Universidade Federal do Rio Grande do Norte (UFRN).

2 Professor da Universidade Federal do Semiárido (UFERSA). Mestre e graduado em Economia pela Universidade Federal do Rio Grande do Norte (UFRN).

${ }^{3}$ Docente do departamento de Economia e do Programa de Pós-Graduação em Economia- UFRN. Doutora em economia pela Universidade Federal de Pernambuco (UFPE).
} 
bibliográfica y utilización del análisis del Cociente Locacional y del instrumental del Análisis Exploratorio de Datos Espaciales (AEDE), en el intento de identificar las aglomeraciones industriales existentes en el territorio potiguar. Aunque la industria de transformación del RN es beneficiada por programas de desarrollo industrial, como el Programa de Apoyo al Desarrollo Industrial de Rio Grande do Norte (PROADI), los resultados apuntaron que durante el período de análisis, el posible desbordamiento esperado entre las áreas vecinas se mostró débil y concentrado en pocas áreas.

Palabras clave: Economía Regional; Empleo Industrial; Dependencia Espacial

\section{INTRODUÇÃO}

As disparidades regionais são a essência dos estudos da Economia Regional. A diferenciação e semelhanças entre as várias regiões levantam o questionamento quanto a necessidade de políticas públicas que contribuam para o desenvolvimento de cada região. De modo geral, o desenvolvimento das atividades em um dado espaço pode determinar as situações de atraso ou sucesso da região, possibilitando que determinados espaços possam ser qualificados como polos industriais de desenvolvimento.

A persistência das desigualdades regionais é um fator preocupante e recorrente na discussão do desenvolvimento brasileiro. Embora o país tenha passado por várias mudanças em sua estrutura produtiva, sob o acirramento concorrencial das empresas pela maior abertura comercial no pós década de 1990, as desigualdades territoriais são visíveis, sejam em âmbito regional ou relacionado às unidades federativas. De modo geral, os resultados abarcam não apenas as questões econômicas, mas implicam no nível social, urbano e ambiental dos espaços.

Alguns autores, como Ferreira (1989, p.57), sugerem que as disparidades econômicas “(...) não resultam do descaso teórico com a economia espacial, mas é resultado da tendência à concentração, à centralização e à aglomeração geográfica da própria organização capitalista da produção". Nota-se que as atividades ocupam um espaço e, em geral, se concentram em determinadas áreas. Estudar os motivos e as possíveis repercussões desse fato é fundamental para o planejamento econômico e social.

No caso brasileiro, o padrão locacional das atividades produtivas é caracterizado por uma elevada diferenciação, reflexo das heterogeneidades presentes nas regiões brasileiras. Essa configuração espacial permite identificar as regiões mais dinâmicas, as que apresentam um leque de serviços mais diversificados, um perfil industrial mais moderno e, portanto, mais 
vantagens locacionais. Por outro lado, as regiões que não apresentam esse conjunto de fatores tendem a concentrar atividades tradicionais e com baixo nível de produtividade.

A indústria no Rio Grande do Norte é um importante setor da economia do estado, tendo contribuído para a economia local ao longo das últimas décadas. Segundo o IBGE (2014), o PIB gerado por tal setor, em 2011, respondeu por aproximadamente $23,7 \%$ do PIB total do estado, destacando-se a indústria extrativa mineral $(8,4 \%)$, seguida da construção civil $(7,2 \%)$ e a indústria de transformação (7\%). Sendo a extração de petróleo e gás natural, alimentos e bebidas, minerais e não metálicos, confecções e produtos têxteis, os principais segmentos industriais. Algumas iniciativas governamentais têm sido adotadas como forma de desenvolver as áreas desfavorecidas, incentivando a localização de indústria no interior do estado. Nesse sentido, destaca-se o Programa de Apoio ao Desenvolvimento Industrial do Rio Grande do Norte (PROADI) criado em 1985 e reformulado em 1997.

Para a análise do desenvolvimento econômico da sociedade se faz necessário conhecer o comportamento dos setores econômicos, principalmente, para compreender a dinâmica das transformações em sua estrutura produtiva e a importância das transformações em tal processo de desenvolvimento.

Desta forma, o presente estudo pretende analisar como o setor industrial, cujo crescimento vem sendo estimulado por programas de desenvolvimento industrial, como o PROADI, tem contribuído para reverter a realidade de estagnação econômica de muitas regiões potiguares. Assim, a abordagem a ser adotada recai sobre os transbordamentos espaciais que o setor apresenta com relação ao emprego formal. Ou seja, a ideia central é identificar se o setor industrial presente em um determinado município do estado influencia a formação de estoque de emprego formal no mesmo setor, mas em um município vizinho. Se houver a ocorrência de tal fato, teríamos que a atividade industrial, mesmo localizada em um dado local, poderia ser capaz de desenvolver a região ao proporcionar o crescimento das áreas vizinhas.

Assim, o objetivo central do presente trabalho é analisar a evolução do emprego formal da indústria de transformação do estado Rio Grande do Norte nos anos 2002 e 2012. Desse modo, o presente trabalho está distribuído em outras cinco seções, além dessa parte introdutória. $\mathrm{Na}$ seção dois será realizada uma revisão da literatura sobre as teorias locacionais das atividades econômicas. Na seção três serão abordadas as políticas de 
incentivos estaduais. Na seção quatro serão discutidos os procedimentos metodológicos e a base de dados utilizada. Por fim, os resultados e considerações finais do trabalho.

\section{CONCENTRAÇÃO DAS ATIVIDADES ECONÔMICAS NO ESPAÇO TEORIAS CLÁSSSICAS DA LOCALIZAÇÃO ESPACIAL}

As teorias clássicas de localização que, de acordo como Monasterio e Cavalcante (2011), podem ser caracterizadas como o conjunto de teorias que evolui desde a publicação de Von Thünen (1826) à teoria de Isard (1956). Ferreira (1989) sintetiza que essas teorias se fundamentam na decisão empresarial sobre o melhor sítio de localização. De modo geral, tais decisões buscam minimizar os custos de operação, especialmente, os gastos com transporte dos insumos e produto final até o mercado consumidor. "Por suas características, tais teorias, eventualmente denominadas teorias neoclássicas da localização e por sua importância e origem histórico-doutrinárias, são teorias clássicas" (FERREIRA, 1989, p. 67).

Observa-se que as investigações sobre a organização territorial das atividades econômica não são recentes, dado que perpassam por questões que envolvem a influência das vantagens geográficas sobre o crescimento das regiões, acesso e fornecimento dos fatores de produção, estrutura produtiva, do ambiente institucional, entre outros.

Na década de 1970, na área da organização industrial surgem os primeiros estudos da "Nova Geografia Econômica" $\left(\mathrm{NGE}^{4}\right)$. Essa literatura se desenvolveu a partir da emergência das aglomerações que se justificavam pela existência dos retornos de escala e custos de transporte (SCHMUTZLER, 1999).

Thisse (2011) evidencia a existência de grandes e pequenas aglomerações de firmas no espaço urbano, “(...) a vida econômica concentra-se em um número relativamente limitado de assentamentos humanos (cidades e aglomerações), os quais estão agrupados sob o título de 'aglomerações econômicas"”. O autor também chama atenção para o fato de que o aparecimento das aglomerações vincula-se ao surgimento das desigualdades espaciais.

Para Isard (1956) a Nova Geografia Econômica remete ao ressurgimento do interesse pelos estudos de localização e espaço econômico. Assim como os teóricos clássicos do estudo

\footnotetext{
${ }^{4}$ É importante enfatizar que, na literatura há algumas críticas e limitações da NGE, entre estas destaca-se Martin (1999, p. 67) ao ressaltar erros na qualificação "Nova Geografia", pois "não é nova, e não é certamente geografia", além da abordagem extremamente matemática para temas já retratados pelos geógrafos. Para o autor, a NGE se limita a agrupar as teorias de localização, a ciência regional e incluir aspectos importantes da teoria moderna de comércio e crescimento.
} 
da localização, o problema de análise da "Nova Geografia Econômica" relaciona-se aos fatores que possuem influência na distribuição geográfica das atividades econômicas.

Dessa maneira, a geografia econômica sustenta-se na "necessidade de explicar as concentrações populacionais e da atividade econômica: a distinção entre regiões industriais e agrícolas, a existência de cidades e o papel das aglomerações de indústrias" (FUJITA et al 2000, p.18). Ou ainda, o estudo condiciona-se a existência de economias de aglomeração, propiciando um ambiente favorável que reforça uma concentração continuada em um dado espaço.

Três autores foram os pioneiros na NGE: Fujita (1989), Krugman (1991) e Venables (1996). Os autores utilizaram os modelos de equilíbrio geral em concorrência monopolística de Dixit e Stiglitz (1977), onde estes desenvolveram seus estudos a partir dos diferentes níveis em que os bens podem ser transportados e nos fatores de localização da indústria que dependiam da dimensão dos retornos de escala e da diferenciação dos produtos (OTTAVIANO e THISSE, 2004).

Defende-se que parte das ideias da NGE fundamenta-se nos trabalhos dos estudiosos da localização. Entretanto, Ottaviano e Thisse (2004) mostram que a NGE tem caráter especial pela modelagem, a partir de um modelo de equilíbrio geral, realizada nas teorias clássicas de localização. Assim, a geografia econômica busca analisar e descrever as transformações econômicas e suas tendências no espaço físico. Pois em qualquer espaço da sociedade, as empresas devem decidir o que, por que, como e onde produzir.

Em suma, os estudos da distribuição das atividades pelas teorias clássicas demonstram ainda no século XIX que a organização das atividades não ocorre de modo uniforme no espaço. Utilizando-se uma visão estritamente microeconômica, via maximização dos lucros e minimização dos custos, assim cada bem e serviço teria sua escala ótima de produção.

Contrapondo-se ao equilíbrio da escola neoclássica, no pós-guerra a preocupação esteve relacionada às desigualdades regionais, e diante disso, a região era vista como um problema, onde a ciência regional estaria encarregada para atender e minimizar as consequências de tais disparidades nas mais diversas regiões. Dessa forma, os teóricos do desenvolvimento regional tiveram influência na formulação de políticas públicas de cunho regional nos anos 1950, 
principalmente, na dualidade existente entre uma região dinâmica e a região periférica (centro-periferia $\left.{ }^{5}\right)$.

A chamada Nova Geografia Econômica (NGE) trouxe a tona a abordagem da localização das atividades no espaço, formalizando a contribuição dos retornos crescentes de escala na decisão locacional. De acordo com Krugman (1980), as interações entre as economias de escala, os custos decorrentes do transporte e a mobilidade dos fatores, criam um ambiente propício à geração de externalidades positivas que poderão gerar vantagens competitivas para a empresa. Entre os exemplos temos a presença de mão de obra qualificada, proximidade entre empresas e maior acesso aos recursos naturais.

Nos últimos anos, os modelos matemáticos desenvolvidos pela NGE têm sido amplamente utilizados em estudos sobre a questão locacional. Assim, muitos estudiosos tem usado a aplicação da NGE para corroborar suas análises ou até mesmo para dá um maior embasamento teórico.

\section{PERFOMANCE DAS POLÍTICAS DE INCENTIVOS FISCAIS NO NORDESTE E NO ESTADO DO RN}

A formação do espaço econômico brasileiro só pode ser compreendida se analisarmos sob a ótica do processo de integração do mercado interno e da política econômica adotada ao longo dos anos. Dessa forma, no caso brasileiro, o Estado por meio das políticas cambiais, de crédito, dos incentivos fiscais e tributários, bem como a dotação de infraestrutura, delineou o desenvolvimento regional recente (PACHECO, 1997).

\footnotetext{
${ }^{5}$ Em 1949, o economista Raúl Prebisch difundiu a tese centro-periferia para expor os problemas do desenvolvimento da América Latina. De modo geral, para Prebisch, a América Latina estava inserida num sistema de relações econômicas internacionais assimétricas, com um centro e uma periferia. Nesse sentido, o Centro pode ser compreendido como os países desenvolvidos produtores de bens manufaturados e historicamente responsável pelo progresso tecnológico, enquanto a Periferia seriam os países em desenvolvimento que são produtores de bens primários ou com baixo grau de industrialização. Portanto, havia uma relação de subordinação da periferia ao centro que produz um desenvolvimento desigual entre as nações, uma vez que nas relações comerciais, os países do centro se apropriavam dos incrementos de produtividade da periferia, gerando uma desigualdade entre os preços dos bens manufaturados do centro e os preços dos produtos primários da periferia em favor dos primeiros. Em outras palavras, haveria uma tendência a deterioração dos termos de troca, ou seja, os preços dos produtos exportados pelos países periféricos tenderiam a perder importância quando comparados aos preços dos bens importados dos países desenvolvidos, o que causaria déficits constantes no balanço de pagamentos em desfavor dos países da periferia capitalista. Neste cenário, emerge a ideia, defendida pela Comissão Econômica para América Latina e o Caribe (CEPAL), da criação de uma nova política de desenvolvimento industrial via substituição de importações que levaria à internalização do setor industrial na periferia e resultaria em um novo processo dinâmico de crescimento orientado para o mercado interno.
} 
O período pós abertura comercial provocou várias mudanças na estrutura econômica do país. Acentuou-se o processo de reestruturação produtiva, reproduzindo fortes impactos na produtividade física e no nível de emprego do país. Muitos desafios foram postos pelas rápidas transformações da atividade produtiva e organização da indústria. Particularmente, é notório que a mudança técnica afeta significativamente os setores da indústria e serviços, alterando as estruturas ocupacionais e o emprego.

Com a incapacidade da intervenção federal na formulação de políticas regionais, coube aos governos estaduais a responsabilidade de iniciativas que buscavam preencher essa lacuna. Em certa medida, o instrumento de política de desenvolvimento seguido pelos estados esteve fundamentado na disputa por investimentos entre as unidades da federação. Isso ocasionou um intenso debate sobre os reais impactos dessa guerra fiscal para os estados e para o país em sua totalidade (LIMA e LIMA, 2010).

Além da alteração do papel do Estado na economia, alguns fatores intensificaram a disputa entre os estados, como foi o caso da promulgação da Constituição Federal de 1988 que marcou o processo de descentralização financeira no Brasil, firmado na necessidade de se elevar a autonomia fiscal dos estados e municípios da nação. Além da maior autonomia fiscal para os estados e municípios, a Constituição Federal pretendia distribuir a responsabilidade das despesas da União para os governos subnacionais.

Ademais, os novos arranjos da economia mundial que demarcaram um processo de abertura econômica no Brasil também acentuaram a guerra fiscal, pois tal política de competição aberta induziu a vinda de capitais internacionais que perseguiam as melhores vantagens locacionais no país. Nota-se que a descentralização política foi perversa, dado que os estados foram relegados a uma disputa por investimentos em um cenário desfavorável, seja em termos de baixo volume de investimentos, ou no que diz respeito ao poder da grande empresa (PACHECO, 1997).

Os programas estaduais possuem características semelhantes, no que tange a geração de emprego ou na interiorização das indústrias. No entanto, deve-se salientar que os incentivos fiscais concedidos não são os únicos fatores levados em consideração no momento da decisão do investimento privado. Vantagens locacionais relacionadas a infraestrutura, mão de obra qualificada, acesso ao mercado consumidor, entre outros fatores, certamente, serão decisivos no momento da escolha alocativa ótima buscada pela indústria. Por conseguinte, a legitimação de medidas mais amplas, como melhorias na qualificação profissional dos 
trabalhados, tornam-se fundamentais para aumento da competitividade local e atratividade (LIMA e LIMA, 2010).

Nesse sentido, no Rio Grande do Norte, o principal programa de desenvolvimento é o Programa de Apoio ao Desenvolvimento Industrial do Rio Grande do Norte (PROADI). Esta iniciativa de industrialização estadual se mostra como uma política autônoma de um projeto (a cargo da União) de desenvolvimento econômico.

O desenho institucional do PROADI é semelhante aos que são praticados na maioria dos estados nordestinos, com inspiração no Financiamento do Nordeste (FINOR). Os incentivos ao investimento industrial via renúncia fiscal do ICMS estão materializados naquele programa. Os segmentos indústrias tradicionais, como a indústria têxtil, que se recuperou da crise de competitividade nos anos 1990, é uma das principias indústrias beneficiadas. Da mesma forma a PETROBRAS com a transformação do petróleo em derivados.

O PROADI tem a finalidade de favorecer o desenvolvimento industrial do RN, concedendo incentivos econômicos para instalação às indústrias. A concessão é feita pelo governo do estado do RN por meio do financiamento do ICMS. Os incentivos podem beneficiar a instalação de novos empreendimentos, como também empresas já existentes que desejam ampliar sua capacidade produtiva.

Podem requisitar os benefícios do PROADI, as empresas industriais que atenderam as seguintes categorias: empresa nova, quando em fase de implantação ou em funcionamento no estado há no máximo seis meses; empresas que necessitam ampliar sua capacidade produtiva em pelo menos $50 \%$ por meio de novos investimentos fixos e circulantes; empresas que se encontram paralisadas a pelo menos doze meses ou ainda que possuam nos últimos sessenta meses anteriores ao pedido de incentivo, capacidade ociosa que represente no mínimo $50 \%$ da capacidade instalada total, caso o critério do Conselho de Desenvolvimento do Estado (CDE) expresse esforço de recuperação através das providências: a) novos investimentos que reconstruam a viabilidade econômica do empreendimento; b) uso da capacidade instalada que torne igualmente possível o empreendimento (ARAÚJO, 2009).

Araújo (2009) também destaca que sem o PROADI as oportunidades de industrialização do estado do RN seriam mais árduas, porque outros estados, da própria região Nordeste, como Ceará, Bahia e Pernambuco, possuem melhores condições de infraestrutura e políticas de incentivos bem mais agressivos. Apesar do PROADI não ter alterado 
significativamente o perfil industrial potiguar, que ainda corresponde aos setores tradicionais, o programa oportuniza a continuidade da industrialização, bem como a permanência das empresas já instaladas.

De acordo com Macedo e Araújo (2008), outro ponto importante é que no tocante aos empregos gerados, o programa teve importância no período de 2003-2007, pois o estoque do emprego formal na indústria de transformação teve um crescimento de 18,3 mil novos empregos. Com 59 projetos aprovados, nesse período, o programa gerou aproximadamente 5.583 empregos, ou seja, o PROADI foi responsável por 31,0\% da variação de empregos na indústria de transformação no período supracitado. Em 2009, esse número chegou a 199 empresas inseridas no programa.

\section{METODOLOGIA}

\section{QUOCIENTE LOCACIONAL}

Inicialmente, para a realização do trabalho serão utilizadas as medidas de localização ${ }^{6}$, que são medidas de natureza setorial e verificam a localização das atividades entre as diversas localidades. O objetivo é identificar padrões de concentração ou dispersão espacial da variável-base do emprego nos subsetores da economia do Rio Grande do Norte nos anos de 2002 e 2012. Com vistas a investigar o perfil urbano e a distribuição do emprego regional no setor, elaboraram-se indicadores para sustentar os argumentos citados e verificar as possíveis modificações locacionais.

$\mathrm{Na}$ análise locacional serão considerados os 8 setores de atividade econômica de acordo com a classificação do IBGE: Indústria Extrativa Mineral, Indústria de Transformação, Comércio, Serviços Industriais de Utilidade Pública, Administração Pública, Agropecuária, Construção Civil e Serviços.

Entre as medidas de localização existentes foi selecionado o Quociente Locacional (QL). Este compara a participação percentual de uma região, em um dos setores, com a participação percentual da mesma região, no total do emprego.

É importante salientar que apesar do QL ser um indicador bastante utilizado, este deve ser elaborado com cautela. Crocco et al (2006), ressaltam que a interpretação dos resultados

\footnotetext{
${ }^{6}$ Para maiores detalhes sugere-se a leitura de: FERREIRA, C.M.C. As teorias de localização e organização espacial da economia. In: HADDAD, P. R. (Org). Economia Regional: Teorias e Métodos de Análise. Fortaleza: Banco do Nordeste do Brasil. ETENE, 1989
} 
deve levar em consideração as particularidades da economia de referência, pois os resultados podem sobrevalorizar o peso de um determinado setor econômico para a região.

Dessa forma, no presente trabalho o uso do Quociente Locacional é justificado como meio de determinar a especialização das atividades específicas numa determinada área. Assim, espera-se que a análise do quociente possibilite a verificação do padrão de crescimento das mesorregiões do $\mathrm{RN}$, e aponte possíveis processos de especialização na estrutura produtiva do estado. Para efeitos deste trabalho, adotou-se o total do emprego no estado do Rio Grande do Norte.

$$
Q L_{i j}=\frac{\frac{E_{i j}}{E_{j}}}{\frac{E_{i e}}{E_{e}}}
$$

Onde:

$E_{i j}$ : emprego no setor $i$ na mesorregião $j$;

$E_{j}$ : emprego total na mesorregião $j$;

$E_{i e}:$ emprego no setor $i$ no estado;

$E_{e}$ : emprego total no estado.

Dessa maneira, o cálculo do QL aponta os setores que cada mesorregião potiguar se concentra economicamente. Dessa maneira: Se QL $\geq 1$, evidencia que o setor em análise é relativamente mais importante na variável emprego para a mesorregião do que para o estado do RN. Conclui-se que a mesorregião pode ser especializada nesse setor; Se $\mathrm{QL}<1$, indica que o setor examinado é menos importante para a mesorregião do que para o estado. Assim, a mesorregião não é especializada naquele setor.

\section{ANÁLISE EXPLORATÓRIA DE DADOS ESPACIAIS (AEDE)}

A presente pesquisa utilizou a Análise Exploratória de Dados Espaciais (AEDE) para analisar a distribuição e associação geográfica da indústria de transformação no RN. Para Anselin (1995), a AEDE possibilita a elaboração de testes espaciais, entre estes temos: o Índice de Moran e o Indicador de Associação Espacial (LISA). 
De acordo com Anselin (2003), a AEDE é um tipo de análise exploratória de dados que faz uso das informações georreferenciadas para explicar padrões espaciais. As diferentes interações no espaço faz com que as informações coletadas possuam duas características denominadas por efeitos espaciais: dependência espacial e heterogeneidade espacial.

Em linhas gerais, a heterogeneidade espacial se refere à existência de instabilidade das relações no espaço, ocasionando diferentes respostas nas diferentes localidades. Almeida (2012) ressalta que várias são as fontes de heterogeneidade espacial, entre elas, teríamos a estrutura espacial, que consiste nas diferenciações nos aspectos políticos, econômicos e institucionais que podem ser distintas em função de onde elas ocorrem.

Por outro lado, a dependência espacial foi estabelecida com a Primeira Lei da Geografia, difundida por Tobler, que enuncia: "Everything is related to everything else, but near things are more related than distant things". Assim, a dependência enfraquece quanto mais se aumenta a dispersão da localização. Verifica-se que há uma relação com a lei da demanda, ao investigar que as interações entre os lugares são inversamente proporcionais ao custo da viagem, no qual a probabilidade de se comprar um bem torna-se inversamente proporcional ao seu custo.

A expressão computacional utilizada para dependência espacial é a autocorrelação espacial, que é derivado do termo correlação, aplicado para mensuração do relacionamento entre duas variáveis aleatórias. Ou seja, a correlação determina o grau de relacionamento entre duas variáveis.

Para Westlund (2013), a lei pode parecer senso comum, entretanto torna-se factível no estudo de um problema em uma determinada região, ao selecionar as variáveis regionais. Outrossim, ao considerar coisas que estão fora de uma região, em termos de acesso ao mercado por um população, em geral, usa-se como parâmetro a distância para mensurar o valor de um bem que está próximo em comparação com esses mesmos bens mais distantes. Ademais, nos últimos anos foram desenvolvidos métodos que lidam com a influência do espaço, por exemplo, os modelos de autocorrelação espacial (idealizados com a $1^{\text {a }}$ Lei da Geografia).

Entre as várias medidas de associação espacial, uma merece destaque pela sua ampla utilização no teste de autocorrelação espacial, o I de Moran. Entre outros testes temos: índice $c$ de Geary (para diferenças globais), G de Getis-Ord, K de Ripley, Indicadores Locais de Associação Espacial (LISA) difundidos por Anselin, entre outros (GETIS, 2008). 


\section{Matriz de Pesos Espaciais}

Nas discussões anteriores vimos como os dados espaciais denotam a variação de fenômenos, preocupando-se onde ocorreu essa variação. Diante disso, para a análise espacial é necessária a definição de uma matriz de pesos espaciais $(w)$ que resume a estrutura de correlação espacial.

Ao especificar uma matriz de ponderação espacial $(w)$ determina-se o arranjo espacial do fenômeno estudado. De acordo com a $1^{\text {a }}$ Lei de Tobler, em que regiões mais próximas possuem maiores interações, cada conexão entre as regiões é representada por uma célula da matriz que é denominada de peso espacial. Um ponto importante está em definir o critério utilizado para quantificar o grau de conexão entre as áreas de análise. Em geral, define-se pela proximidade das regiões (ALMEIDA, 2012). O que não impossibilita que demais critérios, não apenas o geográfico, como aspectos socioeconômicos e culturais que estejam relacionados com o fenômeno estudado.

A matriz de pesos é uma matriz quadrada $(n \times n)$ que apresenta os pesos espaciais de cada unidade sobre a outra. Desse modo, o elemento $w_{i j}$ constitui o peso espacial que a unidade $j$ exerce sobre a unidade $i$, de acordo com o critério de proximidade utilizado.

As estatísticas de Moran estão fundamentadas em vizinhança binária entre as áreas de estudo. Nessas matrizes, atribuíam-se valor 1 para os elementos em que as regiões se encontravam nas respectivas linhas e colunas como vizinhas, ou seja, se possuísse alguma fronteira, ou assumiria valor 0 quando a vizinhança não fosse verificada (GÓMEZ DE ANTONIO, 2008).

Dessa maneira, para um conjunto de $n$ regiões com $\left(P_{1} \ldots . P_{n}\right)$ elementos, na construção da matriz cada elemento representa uma medida de proximidade espacial. Um fato importante é que, como bem salienta Almeida (2012), no desenvolvimento da AEDE é necessário dispor de uma combinação que possibilite a visualização da interação entre os dados espaciais, no caso do presente trabalho, na tentativa de verificar os efeitos de vizinhança ou contiguidade entre os municípios potiguares. A definição de uma matriz de pesos espaciais $(w)$ auxilia na ilustração da estrutura espacial dos dados onde acontece a interação econômica entre os agentes. 


\section{Autocorrelação Espacial Global}

O I de Moran global é um dos testes mais utilizados na literatura para investigação de autocorrelação global, disponibilizando um valor único que possibilita a medição da associação espacial de todo o conjunto de observações características da região de estudo. Isto é, como os valores se correlacionam no espaço.

O índice pode assumir valores que variam de $[-1,+1]$, o que implica em três possíveis resultados: valores com sinal positivo, entre 0 e 1, resulta em autocorrelação espacial positiva, isto é, em uma determina área em que a variável de análise apresente um valor alto haverá áreas vizinhas que também possuem um valor elevado na variável de estudo, o que indica que os dados estão concentrados através dessas regiões; valores com sinal negativo, entre [-1,0], acarretam em autocorrelação negativa, assim, áreas que possuem um valor alto da variável de estudo apresentam como vizinhas regiões que possuem um baixo valor dessa variável e viceversa; valores iguais e próximos a zero apresentam ausência de autocorrelação espacial.

De maneira geral, o I de Moran testa a hipótese nula de independência espacial, quando o índice for igual a zero ou próximo de zero, contra a hipótese alternativa da existência de dependência espacial, quando o $I$ for significativo e diferente de zero. Assim, o valor de $I$ maior (ou menor) do que o valor esperado $E(I)=-1 /(n-1)$ designa que há autocorrelação positiva (ou negativa). Sendo formalmente representado da seguinte forma:

$$
\boldsymbol{I}_{t}=\frac{n}{\sum_{i=1}^{n} \sum_{j=1}^{n} w_{i j}} \frac{\sum_{i=1}^{n} \sum_{j=1}^{n} w_{i j}\left(y_{i, t}-\bar{y}_{t}\right)\left(y_{j, t}-\bar{y}_{t}\right)}{\sum_{i=1}^{n}\left(y_{i, t}-\bar{y}_{t}\right)^{2}}
$$

Em que:

$n$ é o número de regiões ou unidades espaciais;

$w_{i j}$ são os elementos da matriz de pesos espaciais $W$, que mede o grau de interação entre o par de unidades espaciais;

$y_{i, t}$ é a observação na região $i$ no período $t$;

$\bar{y}_{t}$ é a média das observações entre as regiões no período $t$.

A significância estatística $I$ de Moran tem como hipótese nula do teste a ocorrência de aleatoriedade espacial, em geral, os testes são realizados por meio de permutações aleatórias. 


\section{Autocorrelação Espacial Local}

Como visto no item anterior, os indicadores globais possuem um valor único como medida de associação espacial para um conjunto de dados, entretanto, se faz necessário analisar os padrões com um maior nível de detalhe. Nesse sentido, destaca-se o Indicador Local de Associação Espacial - (LISA) na obtenção de um maior detalhamento sobre a área estudada.

A estatística LISA pode ser interpretada por meio do diagrama de dispersão de Moran, que é dividido em quatro quadrantes, conforme a Quadro 1 , onde: $1^{\circ}$ quadrante (Alto-Alto) caracteriza as regiões que apresentam alto nível de uma determinada variável analisada, cujos vizinhos também possuem alto valor da mesma variável; $2^{\circ}$ quadrante (Baixo-Alto), áreas em que a variável apresenta baixo valor, cercados por áreas que apresentam alto valor da variável; $3^{\text {o }}$ quadrante (Baixo-Baixo), áreas cuja variável de análise apresenta um valor baixo, circundada por áreas com valores baixos, por fim, $4^{\circ}$ quadrante (Alto-Baixo), regiões que apresentam altos valores na variável de estudo cercada por áreas com baixos valores.

Quadro 1- Diagrama de Representação da Dispersão de Moran

\begin{tabular}{|c|c|}
\hline Segundo Quadrante (Q2) & Primeiro Quadrante (Q1) \\
Baixo-Alto & (Alto-Alto) \\
\hline Terceiro Quadrante (Q3) & Quarto Quadrante (Q4) \\
Baixo-Baixo & Alto-Baixo \\
\hline
\end{tabular}

Fonte: Elaboração Própria

A medida LISA para cada região i e período $t$ pode ser representada da seguinte maneira:

$I_{i, t}=\frac{\left(y_{i, t}-\bar{y}_{t}\right) \sum_{j=1}^{n} w_{i j}\left(y_{j, t}-\bar{y}_{t}\right)}{m_{0}} \quad$, em que $m_{0}=\frac{\sum_{i=1}^{n}\left(y_{i, t}-\bar{y}_{t}\right)^{2}}{n}$

Onde:

$y_{i, t}$ é a observação de uma variável de interesse na região $i$ para o ano $t$;

$\bar{y}_{t}$ é a média das observações entre as regiões $t$;

$n$ é o número de unidades espaciais;

$w_{i j}$ é o peso espacial para as unidades espaciais $i$ e $j$; 
Portanto, a estatística LISA é relevante para identificação de clusters espaciais locais significantes, ou seja, verificar autocorrelação espacial local positiva. Por outro lado, também pode diagnosticar instabilidade local (outliers espaciais), isto é, autocorrelação espacial local negativa.

\section{DESCRIÇÃO DOS DADOS}

Para a realização do trabalho utilizou-se de dados secundários da Relação Anual de Informações Sociais (RAIS) do Ministério do Trabalho e Emprego (MTE) para os anos 2002 e 2012, do estado do Rio Grande do Norte no tocante ao número de empregos formais na indústria de transformação.

A RAIS tem uma periodicidade anual, sendo coletada pelo Ministério do Trabalho e Emprego (MTE). A base possui um nível de desagregação setorial e espacial bastante elevada, o que possibilita sua utilização em estudos regionais que busquem verificar possíveis tendências de deslocamentos da atividade econômica, aglomerações de empresa, entre outras.

O período de análise da pesquisa será a década compreendida pelos anos 2002 e 2012, justifica-se tal escolha pelas mudanças ocorridas no ambiente econômico ao longo dessa década, bem como, o ano de 2012 representa o período mais atual da obtenção dos dados da RAIS. Para compreender a configuração da IT foram considerados os dados do emprego formal na indústria de transformação conforme os segmentos da Classificação Nacional de Atividades Econômicas (CNAE) de dois dígitos.

\section{ANÁLISE E DISCUSSÃO DOS RESULTADOS DESEMPENHO DA ECONOMIA DO RN NO PERÍODO 2002-2012}

Nesse primeiro momento, foi realizado a análise do Quociente Locacional (QL). Uma vez que os dados sobre o emprego demonstram, ao menos parcialmente, a especialização e se houve algum processo de diversificação no período de estudo. Dessa maneira, serão apresentados e analisados os resultados obtidos da análise das medidas de especialização e concentração para a variável emprego nas mesorregiões do estado do Rio Grande do Norte nos anos 2002 e 2012. Na sequência serão expostos os resultados da autocorrelação espacial global e as estatísticas locais, com a finalidade de averiguar a existência de associação espacial do emprego entre os municípios potiguares, como os clusters e outliers. 


\section{- Indústria Extrativa Mineral}

No subsetor da indústria extrativa mineral, os principais resultados do QL mostraram que as mesorregiões Oeste Potiguar e Central Potiguar apresentaram especialização em 2002 e 2012 na extrativa mineral. Nas mesorregiões Agreste Potiguar e Leste Potiguar não possuem especialização no setor nos dois anos de análise.

Em linhas gerais, a elevada concentração do setor no Oeste Potiguar pode ser explicada pela vocação industrial extrativista de Mossoró, que confirma o município como polo econômico de elevada representação da atividade. A cidade é destaque na extração de petróleo e gás; extração e refino de sal marinho; extração de calcário, sendo o sal e de petróleo (em área terrestre), os principais produtos desta indústria.

\section{- Setor de Comércio}

No setor de comércio, observa-se que nas mesorregiões Oeste Potiguar; Central Potiguar e Agreste Potiguar apresentaram crescimento no QL, nos anos de 2002 e 2012. Dentre essas, as mesorregiões Oeste e Central potiguar passaram a ter especialização em 2012. A mesorregião Leste Potiguar teve sensível queda no QL, mantendo seu nível de concentração estável (vide Figura 4).

\section{- Administração Pública}

Do ponto de vista do PIB, o setor da administração pública é a atividade base da economia do estado, tendo a maior quantidade de trabalhos formais no período de análise. Neste setor, pode-se verificar que nas mesorregiões Oeste Potiguar; Central Potiguar e Agreste Potiguar apresentaram redução em seus QL's, para o setor de Administração Pública, durante o período de análise. Dentre estas, a mesorregião Oeste potiguar foi a que mais perdeu, passando a ser a uma região de baixa especialização em 2012.

\section{- Setor da Agropecuária}

Dentre as mesorregiões, a Oeste potiguar é a que apresentou especialização nos dois períodos de análise. A mesorregião Agreste Potiguar teve o maior salto em seu QL, deixando de ser uma região de baixa especialização para uma região com alta especialização nesse setor. As mesorregiões Leste Potiguar e Central Potiguar não apresentaram especialização nesse setor. 
Em síntese, a alta concentração da agropecuária no Oeste Potiguar decorre, principalmente, da agricultura irrigada presente em Mossoró e Vale do Açu. Esse é o polo dinâmico do setor, pois reúne municípios com peculiaridades distintas na obtenção de água para irrigação e favoráveis ao fomento da atividade. Assim, o ramo da fruticultura irrigada é destaque na agropecuária do estado, por exemplo, o melão potiguar é um dos produtos de grande relevância na pauta exportadora.

\section{- Setor da Construção Civil}

No tocante ao setor de construção civil, a mesorregião Oeste Potiguar e o Leste Potiguar apresentaram especialização nesse setor nos dois anos de análise. As mesorregiões Central Potiguar e Agreste Potiguar tiveram um breve aumento, mas não foi suficiente para apresentar especialização setorial nesses dois espaços. Na mesorregião Oeste Potiguar, o município de Mossoró aparece na primeira posição quanto ao número de empregos gerados, seguido por Alto do Rodrigues e Açu. Esse fato pode ser justificado pela estreita relação entre o setor de construção civil e a urbanização das cidades, já que tais cidades apresentam elevada dinâmica econômica para a mesorregião.

Já no Leste Potiguar, são os municípios de Natal, Parnamirim e São Gonçalo do Amarante, respectivamente, os mais representativos para o setor na mesorregião. Ao longo da década de análise as cidades citadas apresentaram elevado crescimento do setor, com destaque para o município de São Gonçalo do Amarante que teve um incremente de 1200 empregos no ano de 2012. Especialmente, pela dinâmica imobiliária verificada ao longo dessa década nessa mesorregião.

\section{- Setor de Serviços}

O setor de serviços apresentou-se concentrado apenas na mesorregião Leste Potiguar, já que essa engloba a Região Metropolitana de Natal, que é responsável pelo leque de serviços no estado. No entanto, apesar de ser concentrado, o setor apresentou breve redução, refletido através da redução do QL nos anos de análise, pois em 2002 o QL era 1,27; passando para 1,18 em 2012.

A mesorregião Leste Potiguar é a que possui o maior grau de urbanização no estado e também a mais populosa, justificando assim a maior representatividade do setor de serviços, pois esses processos em conjunto elevam a demanda por serviços para atender a necessidade da população local. 


\section{- Indústria de Transformação}

$\mathrm{Na}$ indústria de transformação, observa-se que nas mesorregiões Oeste Potiguar; Central Potiguar e Agreste Potiguar apresentaram ligeiro crescimento no QL, entre 2002 e 2012. Dentre essas, apenas a mesorregião Central Potiguar passou a ter alta especialização em 2012. A mesorregião Leste Potiguar teve sensível queda no QL, mantendo sua concentração a nível estável (Vide Figura 4).

Para a Central Potiguar, o QL variou de 1,07 em 2002 para 1,57 em 2012, tornando a região mais concentrada nesse setor. Os municípios que mais contribuíram para essa concentração, dada sua grande parcela, foram em especial os municípios de Caicó, Parelhas e Guamaré. Respectivamente, com maiores concentrações nos subsetores da indústria têxtil, produtos minerais não metálicos e indústria química. Além disso, os municípios que mais cresceram no setor da IT foram Angicos e Cerro Corá, tornando-os mais representativos, apesar de responderem ainda com uma pequena parcela da atividade.

A mesorregião Leste Potiguar teve uma sensível queda no seu QL, que era de 1,11 em 2002 para 0,99 em 2012. Nesse contexto, a capital do estado, a cidade de Natal, destacou-se na geração de empregos na indústria têxtil, o município de Parnamirim também no subsetor da indústria têxtil e Macaíba com alimentos e bebidas. Dessa forma, os municípios que mais perderam postos de trabalho, contribuindo para um deslocamento a outros setores foram: São Gonçalo do Amarante, Ceará-Mirim e Touros.

A perda de representatividade da indústria de transformação ou o pequeno incremento em algumas mesorregiões do estado indica a desaceleração do setor possivelmente pelos rebatimentos da crise econômica do período de 2008. A ocorrência de excedentes industriais dos diversos países tornou mais lento o desempenho da indústria local. No RN, os três principais ramos que respondem por parcela significativa do emprego formal (aproximadamente 65\% em 2011) são: confecções de artigos de vestuário e acessórios; fabricação de produtos alimentícios e bebidas; e fabricação de produtos minerais não metálicos.

Na Figura 1 é apresentado o perfil setorial nas mesorregiões potiguares, ou seja, os resultados sintetizados através da utilização do Quociente Locacional. Em síntese, alguns setores se mostraram mais especializados em determinadas mesorregiões e com poucas alterações entre os dois anos de análise. Como é o caso do setor da indústria extrativa mineral que se encontra especializado nas mesorregiões Oeste e Central Potiguar (vide Figura 1). 
Figura 1- Quociente Locacional do Emprego para as mesorregiões potiguares (2002 e 2012)

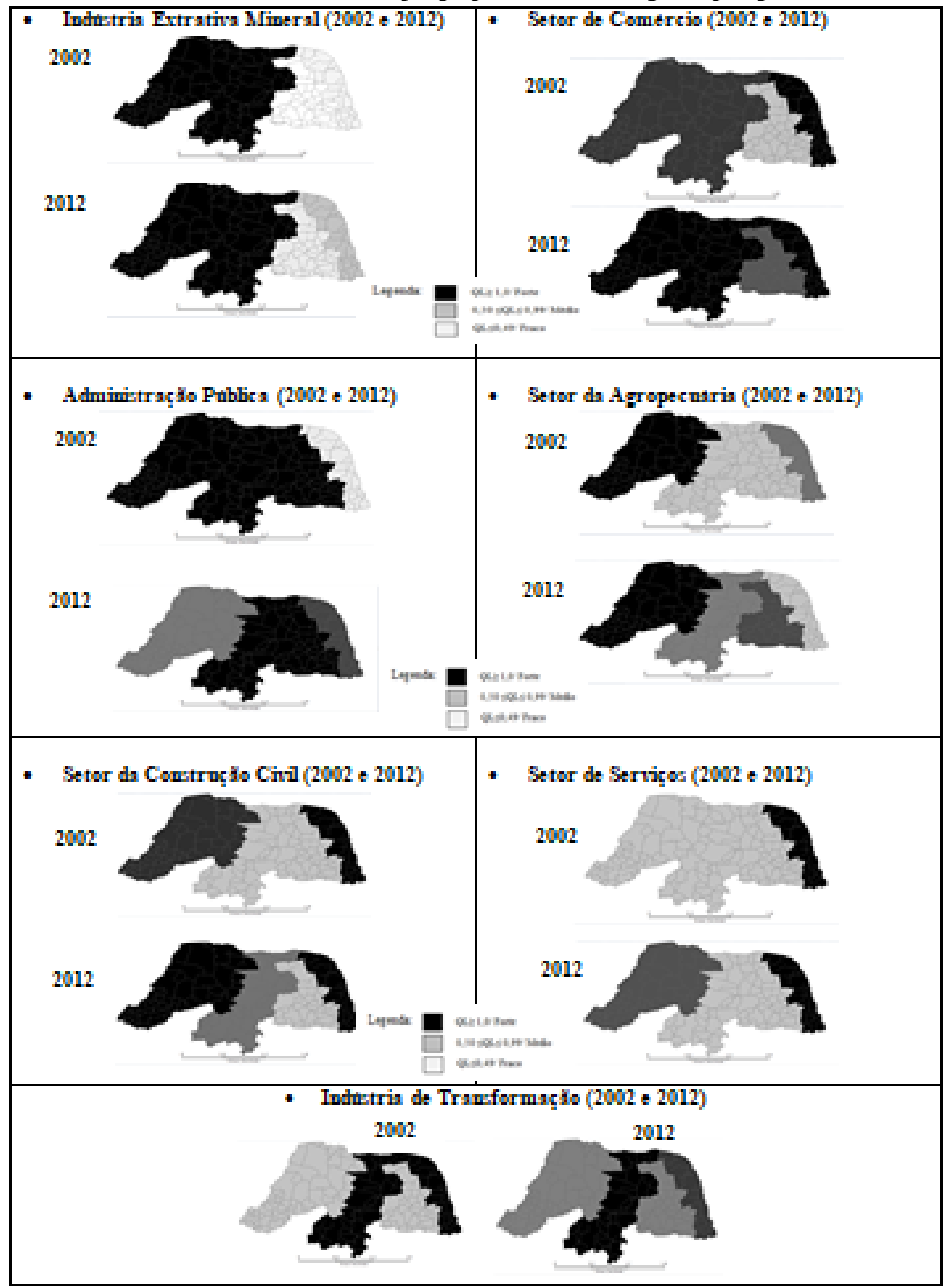

Fonte: Elaboração própria com base nos dados da RAIS/MTE

\section{AUTOCORRELAÇÃO ESPACIAL GLOBAL}

Para a investigação da existência de autocorrelação espacial global nas áreas de análise do trabalho foi calculado o I de Moran. Dessa forma, pode-se constatar a ocorrência ou não de 
aleatoriedade na distribuição do emprego no setor da indústria de transformação. Para isso, utilizou-se a matriz de pesos espaciais do tipo k vizinhos mais próximos, conforme o critério adotado por Baumont et al (2002) ${ }^{7}$.

Os resultados alcançados apontaram e para as diversas matrizes, rejeitou-se a hipótese de aleatoriedade espacial, isto é, o p-valor foi menor que o nível de significância (5\%). Assim, para as matrizes $K=3, K=4$ e $K=5$ nos dois anos de análise, 2002 e 2012, o emprego na indústria de transformação apresenta clusters.

A partir da análise de clusters, pode-se constatar a existência de autocorrelação global positiva quanto ao estoque de emprego formal na indústria de transformação, uma vez que os valores com significância estão localizados na classificação Alto-Alto e Baixo-Baixo. Tal constatação confirma a hipótese de que os municípios com taxas elevadas ou baixas taxas de emprego influenciam municípios vizinhos a terem esse mesmo desempenho, corroborando com a teoria de Tobler, em que quanto mais próximas as áreas, mais relacionadas estão entre si. Outro ponto a observar, é que de acordo com os dados, em ambos os períodos de análise, a distribuição do estoque de emprego no setor da indústria de transformação tem formado aglomerações espaciais ou clusters. Entretanto, para o caso da economia potiguar, as vantagens de vizinhança ainda são reduzidas na formação do estoque de emprego formal dessa atividade no estado.

Para um maior detalhamento da dependência local utilizam-se os indicadores locais que aqui foi selecionado o LISA (Indicador Local de Associação Espacial). Os indicadores locais possibilitam um maior grau de detalhamento ao resultar em um valor específico para cada área. Visto que as estatísticas de autocorrelação espacial global não conseguem identificar a autocorrelação local.

As Figuras 2 e 3 ilustram as áreas estatisticamente significantes para Indústria de Transformação em 2002 e 2012 no estado do Rio Grande do Norte. A análise do LISA possibilita constatar os municípios e a distribuição estadual.

\footnotetext{
${ }^{7}$ Os autores adotam o método de substituição das matrizes espaciais e seleciona o maior e mais significativo valor da estatística I de Moran para os anos de análise.
} 
Figura 2- LISA- Emprego na Indústria de Transformação em 2002

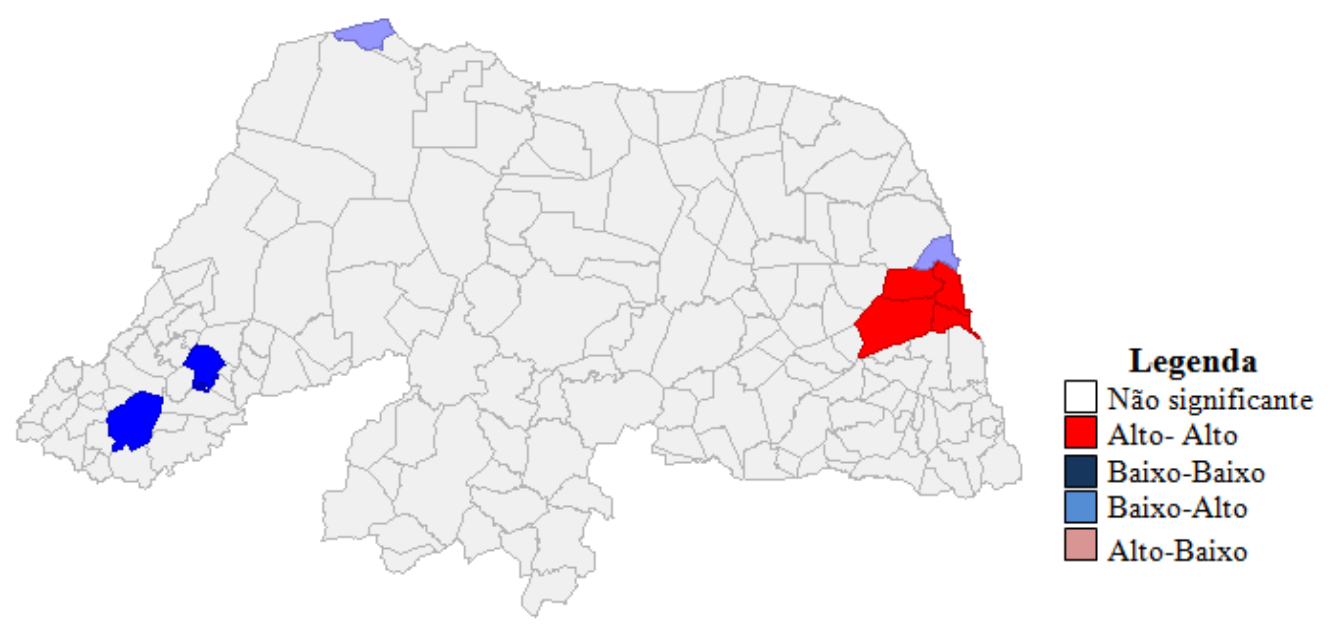

Fonte: Elaboração própria com base nos dados da RAIS/MTE

A figura 2 ilustra o regime espacial no estado em 2002, a associação espacial do tipo AA ocorreu próxima a cidade de Natal, capital do estado do RN. Nesse contexto, foram estatisticamente significantes os municípios de Natal, Parnamirim, Macaíba e São Gonçalo do Amarante, municípios que integram a RMN. Já no ano de 2012, o resultado encontrado foi bastante semelhante na associação AA, entretanto, o município de Macaíba já não se configura nessa associação.

Figura 3- LISA- Emprego na Indústria Transformação em 2012

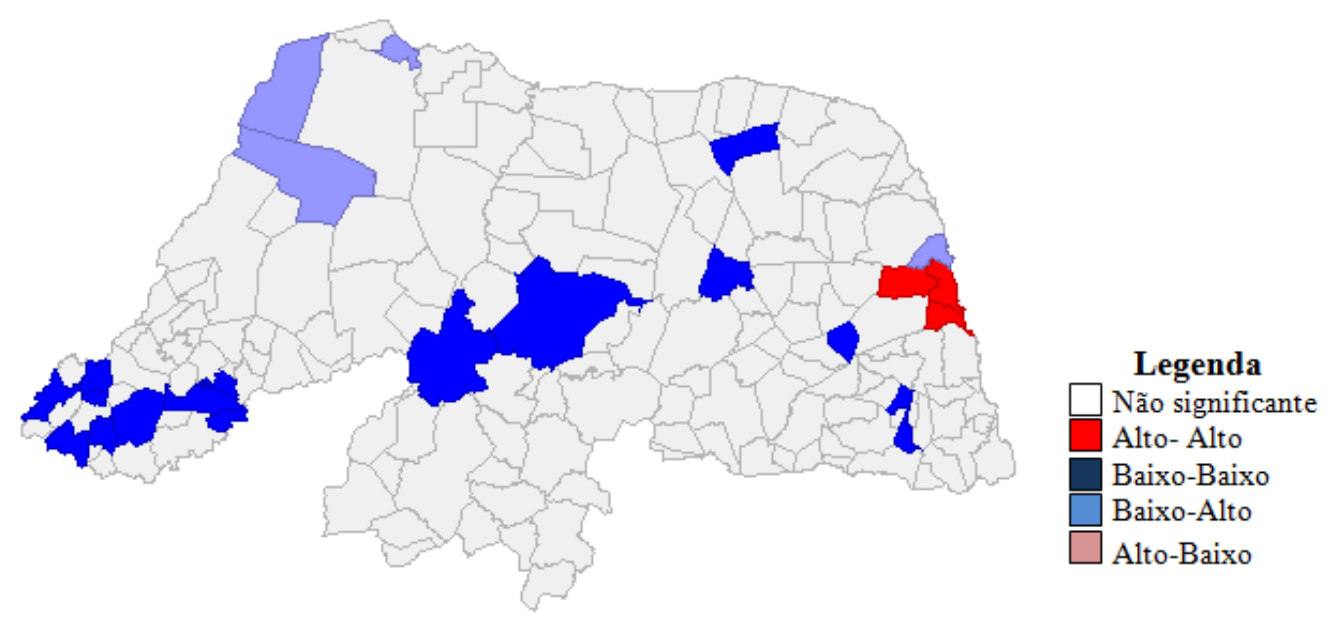

Fonte: Elaboração própria com base nos dados da RAIS/MTE

O cluster tipo BB pode ser visualizado em alguns pontos da Figura 2, o que pode apontar que nesses espaços os municípios com valores baixos de emprego no setor da 
indústria de transformação estão circundados por vizinhos que também apresentam valores baixos. Destacam-se os municípios de Encanto, São Miguel, Marcelino Vieira, Luís Gomes, José da Penha, Antônio Martins e Frutuoso Gomes, pertencentes a mesorregião Oeste Potiguar.

\section{CONCLUSÕES}

O presente trabalho teve como objetivo central analisar a existência de dependência espacial no estoque do emprego formal no setor industrial do estado do Rio Grande do Norte nos anos 2002 e 2012. Pode-se constatar que, nas mesorregiões Leste Potiguar, Central Potiguar e Oeste Potiguar, o setor secundário tem um papel econômico importante para o estado. Os principais setores industriais estão concentrados na região metropolitana de Natal e no município de Mossoró, destacam-se as indústrias de confecção, têxteis e alimentos.

Ao examinar a presença de efeitos espaciais no estoque de empregos formais da indústria de transformação, o trabalho evidencia alguns fatores importantes sobre a temática do desenvolvimento regional potiguar, principalmente quanto ao efeito de transbordamento entre os municípios.

Ao observar os resultados da análise espacial, apenas os municípios da Região Metropolitana de Natal apresentaram uma forte dependência espacial, que possivelmente possui um encadeamento espacial quanto o nível de emprego na indústria de transformação nos dois períodos de análise. Os demais municípios do estado não mostraram um encadeamento espacial no setor o suficiente para a geração de efeitos positivos entre os seus vizinhos, ou acontecera de forma ainda bastante reduzida.

Outro ponto a se destacar é quanto ao crescimento do emprego na indústria de transformação verificado no período de 2002 a 2012, apesar de outros municípios se destacarem na importância do emprego formal no setor, como Mossoró na mesorregião Oeste Potiguar e Caicó na mesorregião Central Potiguar, o aumento do emprego não foi satisfatório para relevância no mapa de autocorrelação espacial, entre outras razões a própria fragilidade dos municípios vizinhos também contribuem para esse resultado.

Com relação ao programa de incentivo estadual, o PROADI, observa-se que os benefícios desse programa não são os únicos fatores determinantes da atração do investimento privado para um município. As vantagens locacionais quanto à infraestrutura, qualificação da mão de obra, entre outros fatores, são fundamentais para escolha de determinada região. 


\section{REFERÊNCIAS}

ALMEIDA, E. Econometria Espacial Aplicada. Campinas: Alínea, 2012.

ANSELIN, L. Local indicators of spatial association - Lisa. Geographical Analysis. n. 27, p. 93-115, 1995.

ANSELIN, L. Spatial externalities, spatial multipliers and spatial econometrics. International Regional Science Review, vol. 26, n. 2, pp. 153-166, 2003.

ARAÚJO, D. S. Dinâmica econômica, urbanização e metropolização no Rio Grande do Norte (1940-2006). Tese de doutorado. Universidade Estadual de Campinas, Instituto de Economia. Campinas, SP, 2009.

BAUMONT, C., ERTUR, C., LE GALLO, J. The European regional convergence process 1980-1995: do spatial regimes and spatial dependence matter? University of Burgundy. 2002. Disponível em: <http://128.118.178.162/eps/em/papers/0207/0207002.pdf>. Acesso em 15 de novembro em 2016.

FERREIRA, C.M.C. As teorias de localização e organização espacial da economia. In: HADDAD, P. R. (Org). Economia Regional: Teorias e Métodos de Análise. Fortaleza: Banco do Nordeste do Brasil. ETENE, 1989.

FUJITA, M. Urban Economic Theory: Land Use and City Size. Cambridge UniversityPress, 1989.

FUJITA, M.; KRUGMAN, P.; VENABLES, A. J. The Spatial Economy: Cities, Regions, and International Trade. Cambridge: Massachusetts Institute of Technology, $2^{\circ}$ printing, 2000.

GÓMEZ DE ANTONIO, M. Econometría Especial: Algunos Aspectos Generales. Disponível em http://www.ucm.es/BUCM/cee/doc/9901/9901.htm. 2008. Acesso em 10 de junho em 2016.

ISARD, W. Location and space-economy. Cambridge: MIT Press, 1956.

KRUGMAN, P. Increasing Returns and Economic Geography. Journal of Political Economy, 99: 483-499. 1991.

LIMA, A. C. C. ; LIMA, J. P. R. Programas de Desenvolvimento Local na Região Nordeste do Brasil: uma avaliação preliminar da guerra fiscal. Economia e Sociedade (UNICAMP. Impresso), v. 19, p. 557-588, 2010.

MACEDO, F. C. de; ARAÚJO, D. da S. Avaliação do Programa de Apoio ao Desenvolvimento Industrial do Rio Grande do Norte (Proadi): 2003/2007. Revista Econômica do Nordeste, Fortaleza, v. 40, n. 2, p. 345-359, abr./jun. 2009.

MARTIN, R. The New Geographical Turn in Economics: Some Critical Reflections, Cambridge Journal of Economics, 23, 65-91, 1999.

MONASTERIO, L. M. ; ÁVILA, R. P. (2004). Análise Espacial do Crescimento Econômico do Rio Grande do Sul (1939-2001). Revista ANPEC, Brasília, DF, v. 5, n. 2, p. 269-296, 2004.

OTTAVIANO, G. I. P; THISSE J. F. "New economic geography: what about the N?" Environment and Planning A 37(10) 1707 - 1725, 2004.

PACHECO, C. A. Desconcentração econômica e fragmentação da economia nacional. Campinas-SP, Revista Economia e Sociedade, n, 6, p. 113-40, jun. 1997. 
PEROBELLI, F. S.; FERREIRA, P. G. C. F.; FARIA, W. R. Análise de convergência espacial no estado de Minas Gerais: 1975-2003. Revista Brasileira de Estudos Regionais e Urbanos, v.1, n.1, maio-out. 2007.

PREBISCH, R. O desenvolvimento econômico da América Latina e seus principais problemas. Revista Brasileira de Economia, n.3, p.47-109. 1949.

SCHMUTZLER, A. (1999): "The new economic geography," Journal of Economic Surveys, 13(4), 355-379.

THISSE, J. F. Economy Geography. CREA Discussion Paper Series 11-01, Center for Research in Economic Analysis, University of Luxemburg, 2011.

VENABLES, A. J. "Equilibrium Location With Vertically Linked Industries", Journal of International Economics, 1996.

VON THÜNEN, J.H. 1826. The Isolated State. Oxford: Pergamon Press, 1966.

WESTLUND, Hans. A brief history of time, space, and growth: Waldo Tobler's first law of geography revisited: WRSA presidential address 2013. The Annuals of Regional Science, Volume 51, no 3, 917-924 pags, 2013.

Recebido em 29 de dezembro de 2017. Aceito em 09 de março de 2018. 